\title{
Does the 45 mm Size Cutoff for Ascending Aortic Replacement Predict Better Early Outcomes in Bicuspid Aortic Valve?
}

\author{
Yi-Jia Li ${ }^{1} \quad$ Wei-Guo Ma ${ }^{2}$ \\ Yue $\mathrm{Qi}^{3} \quad$ Jun-Ming Zhu ${ }^{2}$ \\ ${ }^{1}$ Department of Echocardiography, Beijing Anzhen Hospital, Capital \\ Medical University, and Beijing Institute of Heart Lung and Blood \\ Vessel Diseases, Beijing, China \\ 2 Department of Cardiovascular Surgery, Beijing Anzhen Hospital, \\ Capital Medical University, and Beijing Institute of Heart Lung and \\ Blood Vessel Diseases, Beijing, China \\ ${ }^{3}$ Department of Epidemiology, Beijing Anzhen Hospital, Capital \\ Medical University, and Beijing Institute of Heart Lung and Blood \\ Vessel Diseases, Beijing, China
}

Thorac Cardiovasc Surg 2022;70:289-296.

\author{
Address for correspondence Ya Yang, MD, Beijing Anzhen Hospital, \\ Capital Medical University, Beijing, China \\ (e-mail: yangyaecho@gmail.com).
}

Ya Yang ${ }^{1}$ Li-Zhong Sun ${ }^{2}$ 


\section{Introduction}

In patients with bicuspid aortic valve (BAV) undergoing aortic valve replacement (AVR), there is continued debate regarding the aortic diameter at which prophylactic ascending aortic replacement (AAR) should be performed. ${ }^{1,2}$ Proponents of the $50 \mathrm{~mm}$ cutoff for AAR maintain that aortas in BAV patients with aortic diameter of 40 to $50 \mathrm{~mm}$ undergoing AVR do not dilate, with a low risk of aortic adverse events and mortality. ${ }^{3-8}$ In addition, AVR + AAR is associated with increased risk of mortality, neurologic, and cardiac events, ${ }^{9,10}$ which should be balanced against the benefits of AAR to prevent late complications. A recent American Association for Thoracic Surgery (AATS) Consensus Guidelines on BAV-Related Aortopathy proposed that concomitant AAR be performed when aortic diameter was $\geq 45 \mathrm{~mm}$ in BAV patients undergoing AVR (Class IIa, Level of Evidence B). ${ }^{11}$ In this study, we seek to evaluate whether the $45 \mathrm{~mm}$ size criterion for ascending aortic replacement in BAV patients undergoing AVR was associated with lower surgical risks and improved early outcomes.

\section{Methods}

\section{Ethical Statement}

The Ethics Committees of Beijing Anzhen Hospital of Capital Medical University approved submission and publication of this work and waived the need for informed patient consent (No. 2017015A; October 2017).

\section{Patients}

From January 2008 to December 2017, 658 patients with BAV underwent surgical treatment in our institution. Of these, 306 patients with a diameter of the sinuses of Valsalva [SOV] and/or ascending aorta (AAo) of $\geq 45 \mathrm{~mm}$ underwent AVR alone or with AAR. BAV patients with aortic dissection, congenital heart disease, Behçet and other autoimmune diseases, and connective tissue disorders were excluded. Patients were divided into two groups: AVR + AAR $(n=220)$ and isolated AVR $(n=86)$, based on if surgery was performed in consistence with the $45 \mathrm{~mm}$ criterion. In some patients with fusiform AAo aneurysms, a reduction aortoplasty with or without external wrapping of the AAo was performed as described by Robicsek previously. ${ }^{12}$

\section{Data Collection}

BAV morphology was evaluated by transthoracic echocardiography preoperatively and confirmed by surgical findings. BAV was diagnosed by parasternal long- and short-axis views, showing the existence of only two commissures in systole. Measurement was based on the American Society of Echocardiography guidelines. ${ }^{13,14}$ The Sievers classification scheme was used to categorize BAV morphologies and to distinguish BAV from degenerative fusion of tricuspid aortic valve cusps. $^{15}$

BAV valvulopathy was classified as moderate-to-severe stenosis (m-s-AS), regurgitation (AR) $\geq 2^{+}$, or both (m-s$\mathrm{AS}+\mathrm{AR} \geq 2^{+}$). The degrees of AS and AR were evaluated according to the European Society of Cardiology and European Association for Cardio-Thoracic Surgery Guidelines for the management of valvular heart disease. ${ }^{16}$ The diameters of the SOV and AAo were measured using the leading edgeto-leading edge technique in parasternal long-axis view perpendicular to the centerline of aorta. Dilatation of SOV and AAo was defined as a diameter of $\geq 40 \mathrm{~mm}$. BAV aortopathy was classified as isolated root dilatation (including SOV, aortic valve, and coronary ostia), isolated AAo dilatation, and diffuse dilatation involving root and AAo. ${ }^{17}$

\section{Statistical Analysis}

Continuous variables are expressed as mean \pm standard deviation or median (interquartile range). Categorical variables are expressed as number (percentage). Comparison was made using unpaired Student's $t$ test or Mann-Whitney U test or one-way analysis of variance for continuous variables and chi-squared test or Fisher's exact test for categorical variables.

The study end point was early adverse events (EAE), including in-hospital and 30-day mortality, cardiovascular events (myocardial infarction, ventricular tachycardia or fibrillation, acute heart failure, use of circulatory support devices), acute kidney injury, stroke, and reoperation for bleeding. The impact of conformance to the $45 \mathrm{~mm}$ size criterion on EAE was assessed using proportional Cox hazard models. Adjusted candidate variables are confounding factors that either have been reported more than once with an effect on postoperative $\mathrm{EAE}^{18,19}$ or exhibited significance in univariate analysis, including gender, age, diameters of SOV and AAo, preoperative left ventricular ejection fraction (LVEF), times of cardiopulmonary bypass (CPB) and aortic cross-clamp, Sievers types, and types of BAV valvulopathy.

Propensity score matching was performed to confirm the impact of conformance to the $45 \mathrm{~mm}$ criterion on EAE. A propensity score was first calculated by a logistic regression model based on gender, age, diameters of the SOV and AAo, preoperative LVEF, CPB and cross-clamp times, Sievers types, and types of BAV valvulopathy. Patients with AVR + AAR and isolated AVR were then matched at a 1 to 1 ratio by propensity score using nearest-neighbor matching without replacement, with a caliper of 0.02 . Baseline characteristics and in-hospital management between the two propensitymatched subsets were recompared. As some characteristics did not exactly match between two groups even after propensity matching, multivariable logistic regression was performed to compare the risk by adjusting factors eventually included in the whole study population by stepwise selection. Specifically, a cutoff value at $45 \mathrm{~mm}$ for AAR was adopted to determine whether this size criterion was associated with decreased surgical risks and predicted improved early outcomes.

Statistical analysis was performed using SAS 9.4 (SAS Inc., Cary, North Carolina, United States) and Stata 15.1 for Mac (Stata, College Station, Texas, United States). All tests were two-sided and a $p$-value of $<0.05$ was considered statistically significant. 


\section{Results}

\section{Baseline Characteristics}

Mean age was $52.2 \pm 11.3$ years and 243 were men (73.3\%). The SOV diameter averaged $38.2 \pm 7.5 \mathrm{~mm}$ preoperatively. Preoperative AAo diameter was $49.7 \pm 6.0 \mathrm{~mm}$ and $\geq 50 \mathrm{~mm}$ in $47.1 \%$ (144/306). The mean preoperative LVEF was $0.61 \pm 0.09$. AR $\geq 2^{+}$was seen in $128(41.8 \%)$, m-s-AS in 110 (35.9\%), and $m-s-A S+A R \geq 2$ in 68 (22.2\%). Aortopathy included isolated AAo dilatation in 188 (61.4\%), diffuse dilatation in 110 (35.9\%), and isolated root dilatation in 8 (2.6\%) (-Table 1).
Age, gender, SOV diameter, LVEF, the Sievers types, BAV valvulopathy, and aortopathy did not differ significantly between two groups $(p>0.05)$. Compared with those undergoing AVR + AAR, patients with isolated AVR had significantly smaller AAo diameter $(46.5 \pm 2.7$ vs. $51.0 \pm 6.5 \mathrm{~mm}$, $p<0.001$ ) and were less likely to have an AAo of $\geq 50 \mathrm{~mm}$ (7.6 vs. $92.4 \%, p<0.001$ ) (-Table 1 ).

\section{Clinical Characteristics, Valvulopathy, and Aortopathy by Sievers Types}

Sievers type $1 \mathrm{~L}-\mathrm{R}$ was most common, seen in $62.4 \%$, followed by type $0(20.3 \%)$, type $1 \mathrm{R}-\mathrm{N}$ (14.7\%), and type $1 \mathrm{~L}-\mathrm{N}(2.7 \%)$

Table 1 Baseline characteristics

\begin{tabular}{|c|c|c|c|c|}
\hline Variables & $\begin{array}{l}\text { Total } \\
(n=306, \%)\end{array}$ & $\begin{array}{l}\text { AAR + AVR } \\
(n=220, \%)\end{array}$ & $\begin{array}{l}\text { AVR only } \\
(n=86, \%)\end{array}$ & $p$-Value \\
\hline Age, y & $52.2 \pm 11.3$ & $52.0 \pm 11.1$ & $52.4 \pm 11.9$ & 0.785 \\
\hline Male, $n(\%)$ & $243(73.3)$ & $180(81.8)$ & $63(73.3)$ & 0.096 \\
\hline Body surface area, $\mathrm{m}^{2}$ & $1.8 \pm 0.2$ & $1.8 \pm 0.2$ & $1.8 \pm 0.2$ & 0.175 \\
\hline Systolic blood pressure, $\mathrm{mm} \mathrm{Hg}$ & $124.9 \pm 16.3$ & $124.8 \pm 17.2$ & $125.2 \pm 14.0$ & 0.850 \\
\hline Diastolic blood pressure, $\mathrm{mm} \mathrm{Hg}$ & $72.1 \pm 12.7$ & $72.5 \pm 12.6$ & $71.1 \pm 12.7$ & 0.381 \\
\hline Coronary artery disease, $n(\%)$ & $33(10.8)$ & $23(10.5)$ & $10(11.6)$ & 0.766 \\
\hline \multicolumn{5}{|l|}{ Blood lipid, mmol/L } \\
\hline Triglyceride & $1.3(0.9,1.8)$ & $1.3(0.9,1.9)$ & $1.2(0.9,1.7)$ & 0.722 \\
\hline Total cholesterol & $4.3(3.8,5.0)$ & $4.3(3.8,4.9)$ & $4.4(3.8,5.1)$ & 0.470 \\
\hline High-density lipoprotein & $1.1(0.9,1.3)$ & $1.1(0.9,1.3)$ & $1.1(0.9,1.4)$ & 0.506 \\
\hline Low-density lipoprotein & $2.7(2.1,3.1)$ & $2.7(2.1,3.1)$ & $2.7(2.1,3.2)$ & 0.739 \\
\hline \multicolumn{5}{|l|}{ Echocardiography } \\
\hline SOV diameter, mm & $38.2 \pm 7.5$ & $38.6 \pm 8.1$ & $37.1 \pm 5.9$ & 0.063 \\
\hline AAo diameter, mm & $49.7 \pm 6.0$ & $51.0 \pm 6.5$ & $46.5 \pm 2.7$ & $<0.001$ \\
\hline AAo diameter $\geq 50 \mathrm{~mm}, n(\%)$ & $144(47.1 \%)$ & $133(92.4)$ & $11(7.6)$ & $<0.001$ \\
\hline LVEDD, mm & $57.5 \pm 11.5$ & $57.2 \pm 11.2$ & $58.4 \pm 12.4$ & 0.408 \\
\hline LVESD, mm & $38.6 \pm 10.0$ & $38.2 \pm 9.6$ & $39.7 \pm 11.0$ & 0.250 \\
\hline LVEF & $0.61 \pm 0.09$ & $0.61 \pm 0.08$ & $0.61 \pm 0.09$ & 0.772 \\
\hline BAV Sievers subtypes, $n(\%)$ & & & & 0.772 \\
\hline Type 0 & $62(20.3)$ & $42(19.1)$ & $20(23.3)$ & \\
\hline Type 1 L-R & $191(62.4)$ & $141(64.1)$ & $50(58.1)$ & \\
\hline Type 1 R-N & $45(14.7)$ & $31(14.1)$ & $14(16.3)$ & \\
\hline Type 1 L-N & $8(2.6)$ & $6(2.7)$ & $2(2.3)$ & \\
\hline BAV valvulopathy, $n$ (\%) & & & & 0.699 \\
\hline Moderate-to-severe stenosis (AS) & $110(35.9)$ & $80(36.4)$ & 30 (34.9) & \\
\hline Aortic regurgitation $(A R) \geq 2^{+}$ & $128(41.8)$ & $89(40.5)$ & $39(45.3)$ & \\
\hline $\mathrm{AS}+\mathrm{AR} \geq 2^{+}$ & $68(22.2)$ & $51(23.2)$ & $17(19.8)$ & \\
\hline BAV aortopathy, $n(\%)$ & & & & 0.271 \\
\hline Root dilation only & $8(2.6)$ & $6(2.7)$ & $2(2.3)$ & \\
\hline AAo dilation only & $188(61.4)$ & $129(58.6)$ & $59(68.6)$ & \\
\hline Diffuse dilatation & $110(35.9)$ & $85(38.6)$ & $25(29.1)$ & \\
\hline
\end{tabular}

Abbreviations: AAR, ascending aortic replacement; AVR, aortic valve replacement; BAV, bicuspid aortic valve; SOV, sinuses of Valsalva; AAo, ascending aorta; LVEDD, left ventricular end-diastolic dimension; LVESD, left ventricular end-systolic dimension; LVEF, left ventricular ejection fraction. 

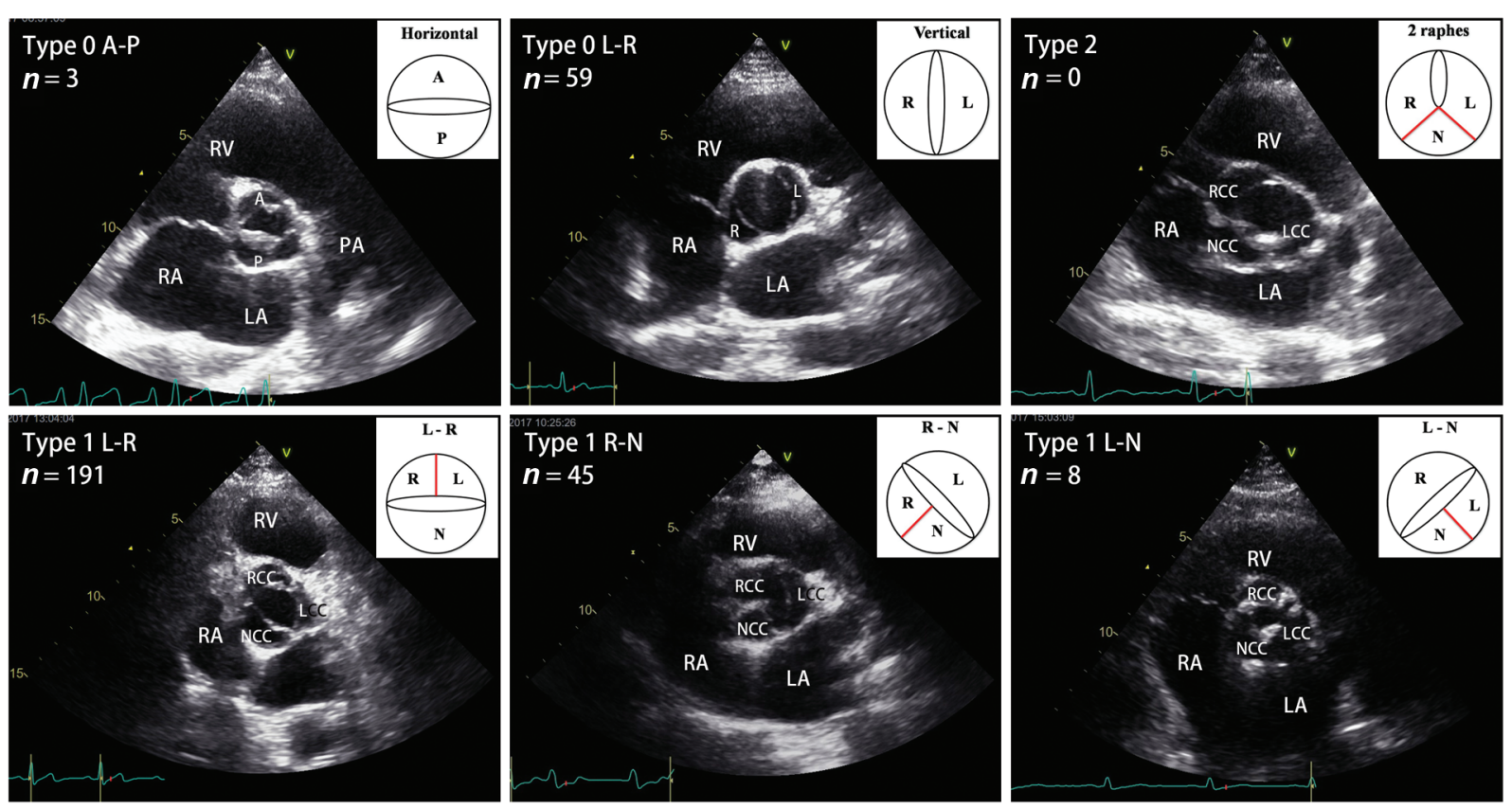

Fig. 1 Sievers types of bicuspid aortic valvulopathy in 306 patients. LA, left atrium; LCC, left coronary cusp; NCC, noncoronary cusp; PA, pulmonary artery; RA, right atrium; RCC, right coronary cusp; RV, right ventricle.

(-Table 1; - Fig. 1). Age, gender, coronary artery disease, and AAo diameter and LVEF did not differ significantly among Sievers subtypes $(p>0.05)$. Patients with type 0 had higher systolic and diastolic blood pressures (127.1 \pm 18.1 and $76.6 \pm 12.2 \mathrm{~mm} \mathrm{Hg})$ compared with other types $(p<0.05)$. The SOV size was largest in type $1 \mathrm{~L}-\mathrm{R}(39.4 \pm 7.8 \mathrm{~mm})$, followed by type $0(36.6 \pm 6.5 \mathrm{~mm})$, type $1 \mathrm{~L}-\mathrm{N}$ $(36.3 \pm 7.5 \mathrm{~mm})$, and type $1 \mathrm{R}-\mathrm{N} \quad(35.6 \pm 6.7 \mathrm{~mm})$ $(p=0.009)$ (-Table 2).

The incidences of valvulopathy $(p=0.019)$ and aortopathy $(p=0.019)$ differed significantly among Sievers subtypes. ms-AS was most common in patients with type 0 (51.6\%). Compared with other types, patients with type $1 \mathrm{~L}-\mathrm{R}$ were more likely to have $\mathrm{AR} \geq 2^{+}$(48.2\%), isolated root dilatation (3.7\%), and diffuse dilatation (42.9\%), but less likely to have moderate-to-severe AS $+\mathrm{AR} \geq 2^{+}(19.4 \%)$ and isolated AAo dilatation (53.4\%). Type $1 \mathrm{R}-\mathrm{N}$ patients had the highest rate of isolated AAo dilatation (77.8\%) and no isolated root dilatation. Moderate-to-severe $+\mathrm{AR} \geq 2^{+}$was most prevalent in type $1 \mathrm{~L}-\mathrm{N}(37.5 \%)$. In patients with type $1 \mathrm{~L}-\mathrm{N}$, the proportions of $\mathrm{m}-\mathrm{s}$-AS $(25 \%)$ and $\mathrm{AR} \geq 2^{+}(25 \%)$ were lowest and none had isolated root dilatation (-Table 2 ).

\section{Operative Data}

The size of the aortic valve prostheses averaged $23.2 \pm 1.8 \mathrm{~mm}$ and did not differ significantly between two groups ( $23.4 \pm 1.9$ vs. $22.9 \pm 1.7 \mathrm{~mm}, p=0.051)$. The median $\mathrm{CPB}$ and cross-clamp times were 122 and 84 minutes, respectively. Circulatory arrest was used in 27 patients (12.5\%) of the group undergoing AAR + AVR, with a mean duration of $16 \pm 7$ minutes (median, 15; range: 7-33). The AVR + AAR group had significantly longer CPB time (128 vs. 111 minutes, $p=0.002)$ and higher postoperative LVEF $(0.59 \pm 0.09$ vs. $0.55 \pm 0.11, p=0.006$ ) (-Table 3).

\section{Early Adverse Events}

EAE occurred in 45 patients (14.7\%), which was significantly higher in isolated AVR group (22.1 vs. $11.8 \%, p=0.020$ ). Operative mortality was $2.0 \%$ (6/306), which did not differ between two groups ( 1.4 vs. $3.5 \%, p=0.335$ ). Operative complications included ventricular tachycardia or fibrillation in 18 (5.9\%), acute heart failure in 9 (2.9\%), use of extracorporeal membrane oxygenation (ECMO) or intraaortic balloon pump (IABP) in 5 (1.6\%), acute myocardial infarction in $1(0.3 \%)$, acute kidney injury in $2(0.7 \%)$, stroke in $3(1.0 \%)$, and reoperation for bleeding in $22(7.2 \%)$ (-Table 4$)$.

\section{Impact of Aortic Size Criterion on Early Adverse Outcomes}

Cox regression models showed that conformance to the $45 \mathrm{~mm}$ size criterion for preemptive AAR during AVR was associated with lower rate of early adverse events (hazard ratio $[\mathrm{HR}] 0.53,95 \%$ confidence interval $[\mathrm{CI}]$ : 0.28-0.98, $p=0.042$ ). Age (in years) was identified as a risk factor for EAE (HR: $1.04,95 \%$ CI: 1.01-1.07, $p=0.011$; adjusted HR 1.05, 95\% CI: 1.01-1.09, $p=0.048)$. After gender, age, SOV and AAo diameter, preoperative LVEF, Sievers types, BAV valvulopathy, and CPB and cross-clamp times were adjusted, conformance to the $45 \mathrm{~mm}$ size criterion for AAR was still predictive of lower EAE rates in the 71 matched pairs (HR: 0.37, 95\% CI: 0.15-0.90, $p=0.028$ ) (-Table 5).

\section{Discussion}

Whether prophylactic AAR would reduce the risk of subsequent aortic dissection or reoperation and the timing of AAR in patients with BAV continues to be debated. Main arguments against preemptive AAR during AVR for BAV patients with moderately dilatated aorta include the increased 
Does the $45 \mathrm{~mm}$ Size Cutoff for Ascending Aortic Replacement Predict Better Early Outcomes in BAV? Li et al. 293

Table 2 Clinical characteristics, valvulopathy, and aortopathy stratified by Sievers subtypes

\begin{tabular}{|c|c|c|c|c|c|}
\hline Variables & $\begin{array}{l}\text { Type } 0 \\
(n=62, \%)\end{array}$ & $\begin{array}{l}\text { Type I L-R } \\
(n=191, \%)\end{array}$ & $\begin{array}{l}\text { Type I R-N } \\
(n=45, \%)\end{array}$ & $\begin{array}{l}\text { Type I L-N } \\
(n=8, \%)\end{array}$ & p-Value \\
\hline Age, y & $52.6 \pm 11.6$ & $55.2 \pm 11.4$ & $51.4 \pm 11.3$ & $51.6 \pm 9.5$ & 0.938 \\
\hline Male, $n(\%)$ & $49(79.0)$ & $154(80.6)$ & $34(75.6)$ & $6(75.0)$ & 0.877 \\
\hline Body surface area, $\mathrm{m}^{2}$ & $1.8 \pm 0.2$ & $1.8 \pm 0.2$ & $1.8 \pm 1.2$ & $1.7 \pm 0.2$ & 0.293 \\
\hline Systolic blood pressure, $\mathrm{mm} \mathrm{Hg}$ & $127.1 \pm 18.1$ & $124.8 \pm 15.5$ & $125.3 \pm 16.5$ & $107.4 \pm 11.3$ & 0.016 \\
\hline Diastolic blood pressure, $\mathrm{mm} \mathrm{Hg}$ & $76.6 \pm 12.2$ & $70.6 \pm 12.6$ & $72.2 \pm 12.7$ & $71.5 \pm 9.7$ & 0.010 \\
\hline Coronary artery disease, $n(\%)$ & $9(14.5)$ & $18(9.4)$ & $6(13.3)$ & $0(0)$ & 0.525 \\
\hline \multicolumn{6}{|l|}{ Echocardiography } \\
\hline SOV diameter, $\mathrm{mm}$ & $36.6 \pm 6.5$ & $39.4 \pm 7.8$ & $35.6 \pm 6.7$ & $36.3 \pm 7.5$ & 0.009 \\
\hline AAo diameter, $\mathrm{mm}$ & $50.3 \pm 5.1$ & $50.0 \pm 4.9$ & $50.0 \pm 4.9$ & $49.1 \pm 3.2$ & 0.453 \\
\hline AAo diameter $\geq 5 \mathrm{~cm}, n(\%)$ & $34(54.8)$ & $83(43.5)$ & 22 (48.9) & $5(62.5)$ & 0.344 \\
\hline LVEDD, mm & $55.4 \pm 11.8$ & $57.8 \pm 10.6$ & $57.8 \pm 10.6$ & $54.1 \pm 12.9$ & 0.168 \\
\hline LVESD, mm & $36.8 \pm 9.9$ & $38.0 \pm 8.8$ & $38.0 \pm 8.8$ & $37.9 \pm 12.0$ & 0.267 \\
\hline LVEF & $0.62 \pm 0.09$ & $0.62 \pm 0.07$ & $0.62 \pm 0.07$ & $0.58 \pm 0.09$ & 0.228 \\
\hline BAV valvulopathy, $n$ (\%) & & & & & 0.019 \\
\hline Moderate-to-severe stenosis (AS) & $32(51.6)$ & $62(32.5)$ & $13(28.9)$ & $2(25.0)$ & \\
\hline Regurgitation $(\mathrm{AR}) \geq 2^{+}$ & $17(27.4)$ & $92(48.2)$ & $17(37.8)$ & $2(25.0)$ & \\
\hline $\mathrm{AS}+\mathrm{AR} \geq 2^{+}$ & $13(21.0)$ & $37(19.4)$ & $15(33.3)$ & $3(37.5)$ & \\
\hline BAV aortopathy, $n(\%)$ & & & & & 0.019 \\
\hline Root dilation only & $1(1.6)$ & $7(3.7)$ & $0(0.0)$ & $0(0.0)$ & \\
\hline AAo dilation only & $45(72.6)$ & $102(53.4)$ & $35(77.8)$ & $6(75.0)$ & \\
\hline Diffuse dilatation & $16(25.8)$ & $82(42.9)$ & $10(22.2)$ & $2(25.0)$ & \\
\hline
\end{tabular}

Abbreviations: AAo, ascending aorta; BAV, bicuspid aortic valve; LVEDD, left ventricular end-diastolic dimension; LVESD, left ventricular end-systolic dimension; LVEF, left ventricular ejection fraction; SOV, sinuses of Valsalva.

Table 3 Operative and postoperative data

\begin{tabular}{|c|c|c|c|c|}
\hline Variables & $\begin{array}{l}\text { Total } \\
(n=306, \%)\end{array}$ & $\begin{array}{l}\text { AVR }+ \text { AAR } \\
(n=220, \%)\end{array}$ & $\begin{array}{l}\text { AVR only } \\
(n=86, \%)\end{array}$ & $p$-Value \\
\hline \multicolumn{5}{|l|}{ Operative } \\
\hline Size of aortic valve prostheses, $\mathrm{mm}$ & $23.2 \pm 1.8$ & $23.4 \pm 1.9$ & $22.9 \pm 1.7$ & 0.051 \\
\hline Cardiopulmonary bypass time, min & $122(100,160)$ & $128(103,166)$ & $111(88,141)$ & 0.002 \\
\hline Aortic cross-clamp time, min & $84(64,108)$ & $85(65,109)$ & $78(60,103)$ & 0.192 \\
\hline Coronary artery bypass grafting, $n(\%)$ & $28(9.2)$ & $17(7.7)$ & $11(12.8)$ & 0.167 \\
\hline Hemiarch replacement, $n(\%)$ & $42(13.7)$ & $42(19.1)$ & $0(0)$ & $<0.001$ \\
\hline \multicolumn{5}{|l|}{ Postoperative } \\
\hline Length of intensive care unit stay, hour & $21(18,26)$ & $21(19,26)$ & $21(17,30)$ & 0.456 \\
\hline Lengths of hospital stay, day & $8(6,11)$ & $8(7,11)$ & $7(6,11)$ & 0.036 \\
\hline Early adverse events, $n(\%)$ & $45(14.7)$ & $26(11.8)$ & $19(22.1)$ & 0.020 \\
\hline Postoperative LVEF & $0.58 \pm 0.1$ & $0.59 \pm 0.09$ & $0.55 \pm 0.11$ & 0.006 \\
\hline Postoperative LVEF <0.5, n (\%) & $48(15.7)$ & $27(12.3)$ & $21(24.4)$ & 0.009 \\
\hline
\end{tabular}

Abbreviations: AVR, aortic valve replacement; AAR, ascending aortic replacement; LVEF, left ventricular ejection fraction. 
Table 4 Early adverse events

\begin{tabular}{|l|l|l|l|l|}
\hline Variables & $\begin{array}{l}\text { Total } \\
(\boldsymbol{n}=\mathbf{3 0 6}, \%)\end{array}$ & $\begin{array}{l}\text { AVR }+ \text { AAR } \\
(\boldsymbol{n}=\mathbf{2 2 0}, \%)\end{array}$ & $\begin{array}{l}\text { AVR only } \\
(\boldsymbol{n}=\mathbf{8 6}, \%)\end{array}$ & $p$-Value \\
\hline Early adverse events, $\boldsymbol{n}(\%)$ & $45(14.7)$ & $26(11.8)$ & $19(22.1)$ & 0.020 \\
\hline Operative mortality, $\boldsymbol{n}(\%)$ & $6(2.0)$ & $3(1.4)$ & $3(3.5)$ & 0.355 \\
\hline Operative complications, $\boldsymbol{n}(\%)$ & & & & \\
\hline Myocardial infarction & $1(0.3)$ & $1(0.5)$ & $0(0)$ & 1.000 \\
\hline Ventricular arrhythmia & $18(5.9)$ & $9(4.1)$ & $9(10.5)$ & 0.054 \\
\hline Acute heart failure & $9(2.9)$ & $6(2.7)$ & $3(3.5)$ & 0.723 \\
\hline Use of ECMO or IABP & $5(1.6)$ & $2(0.9)$ & $3(3.5)$ & 0.137 \\
\hline Acute kidney injury & $2(0.7)$ & $1(0.5)$ & $1(1.2)$ & 0.484 \\
\hline Stroke & $3(1.0)$ & $2(0.9)$ & $1(1.2)$ & 1.000 \\
\hline Reoperation for bleeding & $14(4.6)$ & $7(3.2)$ & $7(8.1)$ & 0.073 \\
\hline
\end{tabular}

Abbreviations: AVR, aortic valve replacement; AAR, ascending aortic replacement; ECMO, extracorporeal membrane oxygenation; IABP, intra-aortic balloon pump.

Table 5 Predictors of early adverse events based on the $45 \mathrm{~mm}$ size cutoff

\begin{tabular}{|c|c|c|c|c|}
\hline \multirow[t]{3}{*}{ Risk factors } & \multicolumn{4}{|c|}{ Hazard ratio ( $95 \%$ confidence interval), $p$-Value } \\
\hline & \multicolumn{2}{|c|}{ Unadjusted analysis } & \multicolumn{2}{|c|}{ Adjusted analysis } \\
\hline & Univariate & Multivariate & Univariate & Multivariate \\
\hline $\begin{array}{l}\text { Conformance to } \\
45 \mathrm{~mm} \text { size cutoff }\end{array}$ & $0.46(0.23-0.93), 0.031$ & $0.53(0.28-0.98), 0.042$ & $0.35(0.14-0.89), 0.028$ & $\begin{array}{l}0.37(0.15-0.90) \\
0.028\end{array}$ \\
\hline Age, y & 1.03 (0.99-1.06), 0.141 & 1.04 (1.01-1.07), 0.011 & 1.03 (0.98-1.09), 0.264 & $\begin{array}{l}1.05(1.01-1.09) \\
0.048\end{array}$ \\
\hline $\begin{array}{l}\text { Systolic blood } \\
\text { pressure, mm Hg }\end{array}$ & 1.00 (0.98-1.02), 0.977 & 0.37 (0.15-0.90), 0.028 & 1.00 (0.96-1.03), 0.785 & \\
\hline $\begin{array}{l}\text { Total cholesterol, } \\
\mathrm{mmol} / \mathrm{L}\end{array}$ & $1.14(0.86-1.52), 0.367$ & 1.05 (1.01-1.09), 0.048 & $1.19(0.81-1.74), 0.370$ & \\
\hline $\begin{array}{l}\text { Aortic cross-clamp } \\
\text { time, min }\end{array}$ & $1.01(1.00-1.02), 0.007$ & 1.01 (1.01-1.02), 0.001 & $1.01(1.00-1.02), 0.221$ & \\
\hline
\end{tabular}

operative risk, the insignificant difference in long-term mortality between patients underwent AVR alone or with $A A R$, and the low risks of adverse aortic events or expansion in dilated AAo after AVR. ${ }^{4,5,7}$ However, increasing data have emerged in support of a smaller size criterion for preemptive AAR during AVR in BAV patients. Reece et al reported similar 30-day mortality rates with isolated and AAR + AVR (3.8 vs. $2.7 \%$ ), suggesting that AAR poses no further risk to BAV patients beyond isolated AVR. ${ }^{9}$ In a series comparing 1,449 patients undergoing BAV surgery alone (AAo $<46 \mathrm{~mm}$ in $95 \%$ ) to 361 patients undergoing valve surgery + AAR (AAo $\geq 41 \mathrm{~mm}$ in $80 \%$ ), similar in-hospital 30-day survival (98.8 vs. $98.9 \%$ ) and stroke rates (1.7 vs. $1.3 \%$ ) were reported. ${ }^{20}$ In 456 patients with BAV, Rinewalt et al found no increase in morbidity or mortality when adding AAR for patients with aortic diameter of $45-49 \mathrm{~mm}$ : while the 30-day mortality was $0.8 \%$ in those with isolated AVR and aortic diameter of $<45 \mathrm{~mm}$, the mortality rates were 0 and $1.9 \%$ with AVR +
AAR for those with aortic diameter of $45-49$ and $\geq 50 \mathrm{~mm}$, respectively. ${ }^{21}$ The landmark research by Borger and associates proved the need for reintervention when AVR alone was performed in the setting of a moderately dilated aorta, 22 based on which an aortic diameter of $45 \mathrm{~mm}$ has been adopted as a criterion for concomitant AAR during AVR for BAV patients.

In the 2018 AATS guidelines, it is recommended that concomitant repair of the AAo or root should be performed when the aortic diameter is $45 \mathrm{~mm}$ or greater during AVR for patients with BAV. ${ }^{11}$ In this context, the present study has validated the efficacy and appropriateness of the $45 \mathrm{~mm}$ size criterion of $45 \mathrm{~mm}$ with respect to the risk of early mortality and morbidity. In this cohort, the mean AAo sizes were 51.0 and $46.7 \mathrm{~mm}$ in the AVR + AAR and isolated AVR groups, respectively. The two groups showed similar rates of inhospital 30-day survival (98.6 vs. $96.5 \%)$ and stroke (0.9 vs. $1.2 \%)$, while the AVR only group sustained more EAE (22.1 vs. 
11.8\%). Most importantly, propensity-adjusted analysis showed that conformance to the $45 \mathrm{~mm}$ criterion for AAR in $B A V$ patients undergoing AVR was predictive of lower rates of EAE. These results show that in this cohort of BAV patients with an aortic diameter of $\geq 45 \mathrm{~mm}$, performing an AAR during AVR based on the $45 \mathrm{~mm}$ cutoff was not associated with increased early mortality and morbidity, suggesting that conformance to the $45 \mathrm{~mm}$ size cutoff may lead to improved early surgical outcomes.

In this cohort, 86 patients who underwent an isolated AVR experienced higher rates of EAE. Although these patients were comparable to the AAR + AVR group in baseline characteristics (-Table 1), these patients may be more severe with respect to other preoperative factors that were not included in the propensity score matching, such as smoking, obesity, diabetes, frailty, chronic renal or hepatic insufficiency, chronic obstructive pulmonary disease, endocarditis, atrial fibrillation, mitral regurgitation, and family history of aortic dissection. ${ }^{19,23,24}$ These risk factors for adverse outcomes may have led the surgeons to avoid the aortic procedure and choose an isolated AVR, which is one of the reasons for the worse early outcomes in patients undergoing an isolated AVR.

While current guidelines and most researches on BAV aortopathy are mainly based on evidence derived from Caucasians, only a few of studies are available on the ethic differences in morphology, valvulopathy, and aortopathy of BAV patients in China or Asia. ${ }^{25-27}$ A recent study shows that Asians have higher prevalence of type 1 of BAV (67\%), larger SOV and AAo body surface area-indexed diameter compared with Europeans (19.6 vs. 18.1 and 20.7 vs. $19.7 \mathrm{~mm} / \mathrm{m}^{2}$, all $p<0.001),{ }^{25}$ which may lead to the different threshold for surgical repair of bicuspid aortopathy. In this cohort, BAV patients were relatively young (mean age: 52.2 years) and type $1 \mathrm{~L}-\mathrm{R}$ was prevalent (62.4\%). AR $\geq 2^{+}$was most common in type $1 \mathrm{~L}-\mathrm{R}$ (48.2\%); AS was most prevalent in type 0 (51.6\%), while type $1 \mathrm{~L}-\mathrm{N}$ had the highest incidence of $\mathrm{m}$ $\mathrm{s}-\mathrm{AS}+\mathrm{AR} \geq 2^{+}$(37.5\%). Isolated root dilatation was relatively rare, most frequent in type $1 \mathrm{~L}-\mathrm{R}(3.7 \%)$. Isolated AAo dilatation and diffuse dilatation were most common in type $1 \mathrm{R}-\mathrm{N}$ (77.8\%) and type $1 \mathrm{~L}-\mathrm{R}$ (42.9\%), respectively. These data show the features of valvulopathy and aortopathy among different Sievers subtypes, which may help illustrate the phenotypes of BAV in the Chinese or Asian population.

This study is limited by its retrospective nature, the small sample size, and the lack of long-term follow-up. Because different surgeons who may use different size criteria, a selection bias cannot be ruled out in which an AVR was performed on some more severe patients who should have been treated with AAR + AVR. Although the two groups were propensity matched in baseline characteristics, other important factors affecting surgical decision making and operative outcomes, ${ }^{19}$ such as AAo growth rate $\geq 5 \mathrm{~mm} /$ year, family history, ${ }^{23,24}$ mitral regurgitation, preoperative atrial fibrillation, diabetes, and chronic renal disease, were not included in the propensity score matching. It is questionable if the sample size is able to show a noninferiority outcome given these potential biases. Lack of long-term follow-up data precludes the possibility of assessing if the $45 \mathrm{~mm}$ size criterion was associated with improved long-term outcomes concerning survival, reoperation, and adverse events. Furthermore, this study represents our single-center experience only and further validation of the $45 \mathrm{~mm}$ size criterion in multicenter settings is warranted.

\section{Conclusions}

This study shows that conformance to the $45 \mathrm{~mm}$ size cutoff for preemptive ascending aortic replacement during AVR in BAV patients was not associated with increased risk for EAE, which suggests that the size criterion for prophylactic ascending aortic replacement may need to be lowered to $45 \mathrm{~mm}$ in such patients to improve early surgical outcomes.

\section{Disclosure}

Authors have nothing to disclose with regard to commercial support and source of funding.

\section{Conflict of Interest}

None declared.

\section{References}

1 Etz CD, Homann TM, Silovitz D, et al. Long-term survival after the Bentall procedure in 206 patients with bicuspid aortic valve. Ann Thorac Surg 2007;84(04):1186-1193, discussion 1193-1194

2 Nardi P, Pellegrino A, Russo M, Saitto G, Bertoldo F, Chiariello L. Midterm results of different surgical techniques to replace dilated ascending aorta associated with bicuspid aortic valve disease. Ann Thorac Surg 2013;96(05):1648-1654

3 McKellar SH, Michelena HI, Li Z, Schaff HV, Sundt TM III. Longterm risk of aortic events following aortic valve replacement in patients with bicuspid aortic valves. Am J Cardiol 2010;106(11): 1626-1633

4 Abdulkareem N, Soppa G, Jones S, Valencia O, Smelt J, Jahangiri M. Dilatation of the remaining aorta after aortic valve or aortic root replacement in patients with bicuspid aortic valve: a 5-year follow-up. Ann Thorac Surg 2013;96(01):43-49

5 Hardikar AA, Marwick TH. Surgical thresholds for bicuspid aortic valve associated aortopathy. JACC Cardiovasc Imaging 2013;6 (12):1311-1320

6 Charitos EI, Stierle U, Petersen M, et al. The fate of the bicuspid valve aortopathy after aortic valve replacement. Eur J Cardiothorac Surg 2014;45(05):e128-e135

7 Kaneko T, Shekar P, Ivkovic V, et al;Bicuspid Aortic Valve Consortium (BAVCon) Should the dilated ascending aorta be repaired at the time of bicuspid aortic valve replacement? Eur J Cardiothorac Surg 2018;53(03):560-568

8 Lee SH, Kim JB, Kim DH, et al. Management of dilated ascending aorta during aortic valve replacement: valve replacement alone versus aorta wrapping versus aorta replacement. J Thorac Cardiovasc Surg 2013;146(04):802-809

9 Reece TB, Singh RR, Stiles BM, et al. Replacement of the proximal aorta adds no further risk to aortic valve procedures. Ann Thorac Surg 2007;84(02):473-478, discussion 478

10 Girardi LN, Krieger KH, Mack CA, Lee LY, Tortolani AJ, Isom OW. Reoperations on the ascending aorta and aortic root in patients with previous cardiac surgery. Ann Thorac Surg 2006;82(04):1407-1412

11 Borger MA, Fedak PWM, Stephens EH, et al. The American Association for Thoracic Surgery consensus guidelines on bicuspid aortic valve-related aortopathy: Full online-only version. J Thorac Cardiovasc Surg 2018;156(02):e41-e74 
12 Robicsek F. A new method to treat fusiform aneurysms of the ascending aorta associated with aortic valve disease: an alternative to radical resection. Ann Thorac Surg 1982;34(01):92-94

13 Gardin JM, Adams DB, Douglas PS, et al; American Society of Echocardiography. Recommendations for a standardized report for adult transthoracic echocardiography: a report from the American Society of Echocardiography's Nomenclature and Standards Committee and Task Force for a Standardized Echocardiography Report. J Am Soc Echocardiogr 2002;15(03):275-290

14 Hahn RT, Abraham T, Adams MS, et al; American Society of Echocardiography Society of Cardiovascular Anesthesiologists. Guidelines for performing a comprehensive transesophageal echocardiographic examination: recommendations from the American Society of Echocardiography and the Society of Cardiovascular Anesthesiologists. Anesth Analg 2014;118(01):21-68

15 Sievers HH, Schmidtke C. A classification system for the bicuspid aortic valve from 304 surgical specimens. J Thorac Cardiovasc Surg 2007;133(05):1226-1233

16 Baumgartner H, Falk V, Bax JJ, et al. 2017 ESC/EACTS guidelines for the management of valvular heart disease. Rev Esp Cardiol (Engl Ed) 2018;71(02):110

17 Fazel SS, Mallidi HR, Lee RS, et al. The aortopathy of bicuspid aortic valve disease has distinctive patterns and usually involves the transverse aortic arch. J Thorac Cardiovasc Surg 2008;135(04): 901-907, 907.e1-907.e2

18 Kong WK, Regeer MV, Ng AC, et al. Sex differences in phenotypes of bicuspid aortic valve and aortopathy: Insights from a large multicenter, international registry. Circ Cardiovasc Imaging 2017; 10(03): 10
19 Verma S, Siu SC. Aortic dilatation in patients with bicuspid aortic valve. N Engl J Med 2014;370(20):1920-1929

20 Svensson LG, Kim KH, Blackstone EH, et al. Bicuspid aortic valve surgery with proactive ascending aorta repair. J Thorac Cardiovasc Surg 2011;142(03):622-629, 629.e1-629.e3

21 Rinewalt D, McCarthy PM, Malaisrie SC, et al. Effect of aortic aneurysm replacement on outcomes after bicuspid aortic valve surgery: validation of contemporary guidelines. J Thorac Cardiovasc Surg 2014;148(05):2060-2069

22 Borger MA, Preston M, Ivanov J, et al. Should the ascending aorta be replaced more frequently in patients with bicuspid aortic valve disease? J Thorac Cardiovasc Surg 2004;128(05):677-683

23 Ma WG, Chou AS, Mok SCM, et al. Positive family history of aortic dissection dramatically increases dissection risk in family members. Int J Cardiol 2017;240:132-137

24 Dayan V, Zuasnabar A, Citro R, et al; Bicuspid Aortic Valve Consortium - BAVCON. Aortopathy and regurgitation in bicuspid valve patients increase the risk of aortopathy in relatives. Int J Cardiol 2019;286:117-120

25 Kong WKF, Regeer MV, Poh KK, et al. Inter-ethnic differences in valve morphology, valvular dysfunction, and aortopathy between Asian and European patients with bicuspid aortic valve. Eur Heart J 2018;39(15):1308-1313

26 Liu F, Yang YN, Xie X, et al. Prevalence of congenital heart disease in Xinjiang multi-ethnic region of China. PLoS One 2015;10(08): e0133961

27 Li Y, Wei X, Zhao Z, et al. Prevalence and complications of bicuspid aortic valve in Chinese according to echocardiographic database. Am J Cardiol 2017;120(02):287-291 